\title{
In memoriam: Dr. Beth Levine (1960-2020)
}

\author{
Jennifer Martinez ${ }^{1}$
}

Received: 3 July 2020 / Accepted: 7 July 2020 / Published online: 24 July 2020

(c) The Author(s), under exclusive licence to ADMC Associazione Differenziamento e Morte Cellulare 2020

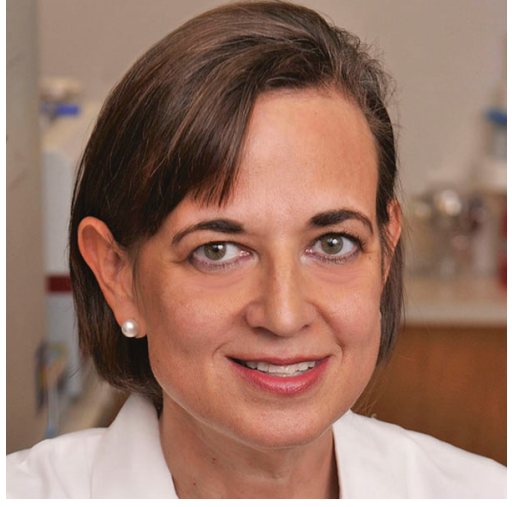

In the beginning, there was Beclin $1 \ldots$ and Dr. Beth Levine.

On June 15, 2020, our friend and colleague, Dr. Beth Levine of the University of Texas Southwestern (UTSW) Medical Center died after a long-fought and courageous battle with breast cancer. She is survived by her husband and two children, and leaves behind an illustrious and inspirational legacy that revealed key insights into how cells fine-tune the balance between homeostasis and stress and navigate the decision between survival and cell death.

Born in Newark, New Jersey, Beth earned her Bachelor's of Arts in French Studies from Brown University in 1981. Her joie de vivre would manifest itself as a clinical researcher, though, as she earned her medical degree from Weill Cornell University in 1986, followed by a residency in internal medicine at Mount Sinai Hospital until 1989. It was during her residency that Beth's aptitude for infectious disease and immunopathology first shined, culminating in a

Jennifer Martinez

jennifer.martinez3@nih.gov

1 Immunity, Inflammation, and Disease Laboratory, National Institute of Environmental Health Sciences, Research Triangle Park, NC 27709, USA publication in the New England Journal of Medicine on the association of increased inflammatory mediators, such as tumor necrosis factor, in patients with severe cardiac failure. Beth's path then led her to the laboratory of Dr. Diane Griffin at Johns Hopkins University, where her postdoctoral fellowship focused on the neuroimmunological response to viral infection, specifically Sindbis virus, a single-stranded RNA virus in the alphavirus genus. Beth's pioneering work on the control of alphavirus encephalitis, featured in Science and Nature, converged with the cell death expertise of Dr. J. Marie Hardwick, also at Johns Hopkins University. It was this collaboration that unveiled the role of the antiapoptotic molecule, BCL-2, in antiviral immunity, and serendipitously, led Beth to her research destiny.

Autophagy (from the Greek for "self-eating") is an evolutionarily conserved catabolic pathway to degrade, process, and recycle cellular components during times of starvation or stress. While Dr. Yoshinori Oshumi had already described this critical system in yeast, its functions and regulation in mammalian cells were under-described and, worse, under-appreciated.

Armed with the knowledge that expression of BCL-2 resulted in decreased alphavirus replication and virusinduced cell death, Beth led her team at Columbia University to study BCL-2 -interacting proteins that confer protection during viral infection. In 1998, her group identified Beclin-1, so named because of its interaction with BCL-2 ("Becl" and its coiled-coil structure ("-in" suffix). This groundbreaking discovery paved the way for Beth to dramatically change our understanding and appreciation of how autophagy impacts mammalian development and pathology. As her group would demonstrate in 1999, Beclin-1 is the mammalian homolog of Apg6 in yeast and a necessary component of mammalian autophagy. Not only is Beclin-1 required for autophagy, it is a potent tumor suppressor, with Beclin-1-heterozygote mice developing spontaneous tumors-a phenotype not observed in other autophagy-deficient models. Indeed, $\sim 50 \%$ of sporadic human breast and ovarian cancers exhibit mono-allelic deletion of Beclin-1. 
This breakthrough sparked a renaissance of autophagy research. Today, Beclin-1 is the most studied mammalian autophagy gene, and over the course of her career, Beth's elegant work demonstrated not only the phenotype of Beclin-1 deficiency, but also the many molecular mechanisms regulate Beclin-1 expression and activity. Tumor cells actively employ multiple mechanisms to incapacitate Beclin-1. Similarly, pathogens, such as alphaviruses, Salmonella typhimurium, and herpes simplex virus, also antagonize Beclin-1 to promote their unfettered propagation. Moreover, an organism's ability to retain functional Beclin-1 is positively associated with increased longevity and decreased disease incidence. Her most recent work describes the crosstalk among three seemingly disparate pathways (TLR9 signaling, Beclin-1/autophagy, and AMPK activation) and their interconnected role in mediating glucose metabolism during exercise. Motivated by her medical background, Dr. Levine developed a Beclin-1activating peptide, Tat-Beclin-1, capable of activating Beclin-1 and autophagy both in vitro and in vivo. To date, this candidate therapeutic has demonstrated efficacy in models of viral infection, HER2-medaited breast cancer, cardiac failure, retinal ischemia, infertility, stroke, and cognitive dysfunction. How can a single molecule undertake so much responsibility?

Simply put, Beclin-1 is special. And only a special researcher, like Beth Levine, could reveal the uniqueness and potential of Beclin-1, as a highly conserved core mediator of the stress response and a key guardian of cellular quality and survival, beyond what other autophagy genes are capable of.
Throughout her distinguished career, Beth led-as a group leader and as an institute leader. In 1994, at the age of 34, Beth began a decade-long tenure as Director of Virology Research at Columbia University. In 2004, she was recruited to the University of Texas Southwestern Medical Center as the Chief of the Division of Infectious Diseases and the Jay P. Sanford Professor in Infectious Diseases. In 2008, she began serving as a Howard Hughes Medical Institute Investigator. In 2011, her passion for autophagy culminated in the creation of UTSW's Center for Autophagy Research, with Beth at the helm. That leadership would not have been possible-or successful-without the elegance, empathy, and magnetism that defined Beth. Her support, vision, and humanity guided dozens of trainees through their early scientific careers, and her character and intellect guided thousands more, as they read her papers with wide-eyed awe and were held captive by her sophisticated, yet accessible lectures.

I am one of those thousands. As a woman in science, no less the field of autophagy, I cannot put into words the impact that Beth Levine has had on me, as a scientist and a woman. To see her behind the podium, to hear the dedication to her art in her voice, to witness her strength as a leader, to marvel at her innovation, these were gifts to me and countless others. John Quincy Adams once said "If your actions inspire others to dream more, learn more, do more, and become more, you are a leader." Dear Beth, you have inspired us to dream more, learn more, do more, and be more. You are a true leader, and you will live on in hearts and our minds. 